\title{
Finite element analysis of the sap flow measurement method with continuous needle heating in the sapwood of trees
}

\author{
M. Trcala ${ }^{1} \&$ J. Čermák ${ }^{2}$ \\ ${ }^{1}$ Department of Wood Science, \\ Mendel University in Brno, Czech Republic \\ ${ }^{2}$ Department of Forest Botany, Dendrology and Geobiocenology, \\ Mendel University in Brno, Czech Republic
}

\begin{abstract}
Water flow represents the biggest energy flow in vegetation which also causes its magnificent climatic effect. From all the water taken up by plants, the majority is transpired, leading to leaf cooling (associated with the heat of vaporization) and only minor amounts of water are consumed by all the other processes (such as photosynthesis transport of assimilates, growth, etc.). The transpiration can be estimated through the measurement of sap flow rates in a tree stem. A series of measurement methods were developed for this purpose and they are mostly based on thermodynamic principles.

This paper deals with the numerical analysis of the sap flow measurement method based on the continuous needle heating of a stem segment, the measurement of temperature differences using the thermocouples around the heated domain and sap flow calculation from the temperature differences. An appropriate model of heat transfer in the sapwood of trees is derived and solved. The model is based on a partial differential equation describing conductionconvection heat transfer during continuous linear heating and it is solved by the finite element method.

Keywords: heat conduction-convection, sap flow measurement, finite element method, continuous needle heating.
\end{abstract}




\section{Introduction}

The measurement of water use by plants, especially by trees, is needed for many purposes in forestry, ecology, hydrology and microclimatology. This is why several methods for field measurement of the ascending water flow (sap flow) through a plant stem were developed (presented in chronological order): (1) heat pulse velocity $[2,5,6,8-10,11,14,15,21,25]$; (2) trunk segment heat balance [3, 4, 23, 24]; (3) stem heat balance [1, 19, 20]; (4) heat dissipation [7]; and (5) heat field deformation [16-18]. These methods are thermodynamic (in practice only thermodynamic methods for sap flow measurement are used) and are based on the same physical principle. A certain part of conductive woody tissue is heated and heat dissipation is assessed from temperature measurements [22]. There are two main groups of the thermodynamic methods (1) with continuous heating and (2) with heat pulses. The methods can be also divided into methods with linear, plate, and volume heating [22]. The most often the linear (needle) heating is used for both cases - continuous heating and heat pulses.

This work addresses the problem of sap flow measurement with continuous needle heating inspired by Leyton [12, 13]. For large trees Leyton developed a double heated plate technique based on the exchange of heat between the moving sap and two permanently heated plate units (about 1 x $1 \mathrm{~cm}$ ) inserted vertically, one above the other, along the stem radius in the sapwood. A battery of thermocouples was inserted within the heated units. The unit (containing resistance wires of $2 \mathrm{ohms}$ ) were heated continuously by a current about $200 \mathrm{~mA}$ and their difference in temperature $\left(T_{\text {upper }}-T_{\text {lower }}\right)$ recorded. An extra thermocouple is incorporated in the lower unit and connected to a similar thermocouple in the stem, well below the unit, to allow the temperature difference between this unit and the "cool" sap $\left(T_{\text {cool }}\right)$ to be recorded at the same time $\left(T_{\text {lower }}-T_{\text {cool }}\right)$. The sap flow rate is calculated on the basis of following assumptions: Because the sap is somewhat warmer when it reaches the top unit than when it reached the lower unit, there will be less heat taken from the upper and its temperature will be higher than that of the lower unit. It can be shown by thermodynamic argument, that the ratio of temperatures given below is a sole function of the sap flux $\left(Q_{w}, \mathrm{~m}^{3} / \mathrm{s}\right)$ past the units

$$
Q_{w}=\frac{T_{\text {upper }}-T_{\text {lower }}}{T_{\text {lower }}-T_{\text {cool }}} .
$$

Theoretically, the Leyton method is simple and promising. The author found a good fit with data measured by weighing. A practical drawback of the method is that the heating plates are composite and thus vulnerable, which means that it may not be easy to incorporate them deep into xylem. The author sees the difficulty in establishing the exact area of sapwood around the units that is concerned with the exchange of heat; if that area is not known, the method must be calibrated before total sap flux in the stem can be determined. Instead of the double heated plate system we tested a double heated needle system as shown in Figure 1. 


\section{Governing equations}

This analysis was done using the numerical solution of a three-dimensional problem of heat transfer in the anisotropic structure of sapwood during sap flow measurement using continuous two-needle heating of a stem. The simulation is based on the steady-state conduction and convection of heat with respect to the orthotropic nature of wood. A matrix form of this model was derived and numerical simulations were performed. These simulations were obtained by COMSOL Multiphysics with MATLAB and are based on solving partial differential equation by the finite element method. The partial differential equation is the following $[23,24]$ :

$$
\rho c \frac{\partial T}{\partial t}=\nabla \cdot \lambda \nabla T+c_{w} \mathbf{Q}_{\mathbf{w}} \cdot \nabla T+P,
$$

where

$$
\boldsymbol{\lambda}=\left(\begin{array}{ccc}
\lambda_{R} & 0 & 0 \\
0 & \lambda_{T} & 0 \\
0 & 0 & \lambda_{L}
\end{array}\right), \mathbf{Q}_{w}=\left(\begin{array}{lll}
Q_{w x} & Q_{w y} & Q_{w z}
\end{array}\right) \equiv\left(\begin{array}{lll}
0 & 0 & Q_{w}
\end{array}\right)
$$

and $\nabla$ denotes the vector differential operator $\nabla=\left(\begin{array}{lll}\partial / \partial x, & \partial / \partial y, & \partial / \partial z\end{array}\right)$.

After substituting and modifications we get this form of the above mentioned partial differential equation:

$$
\rho c \frac{\partial T}{\partial t}=\frac{\partial}{\partial x}\left(\lambda_{R} \frac{\partial T}{\partial x}\right)+\frac{\partial}{\partial y}\left(\lambda_{T} \frac{\partial T}{\partial y}\right)+\frac{\partial}{\partial z}\left(\lambda_{L} \frac{\partial T}{\partial z}\right)+c_{w} Q_{w} \frac{\partial T}{\partial z}+P
$$

where $T$ is temperature (K), $Q_{w}$ is sap flow density $\left(\mathrm{kg} \mathrm{m}^{-2} \mathrm{~s}^{-1}\right), \lambda$ is matrix of heat conductivity coefficients of fresh sapwood $\left(\mathrm{W} \mathrm{m}^{-1} \mathrm{~K}^{-1}\right), \rho$ is density of fresh sapwood $\left(\mathrm{kg} \mathrm{m}^{-3}\right), c$ is specific heat of fresh sapwood $\left(\mathrm{J} \mathrm{kg}^{-1} \mathrm{~K}^{-1}\right), c_{w}$ is specific heat of water $\left(\mathrm{J} \mathrm{kg}^{-1} \mathrm{~K}^{-1}\right), P$ is heat power $\left(\mathrm{W} \mathrm{m}^{-3}\right)$.

For steady-state the derivative of a temperature with respect to time is equal to zero and the previous equation is simplified into this form:

$$
\nabla \cdot \lambda \nabla T+c_{w} \mathbf{Q}_{\mathbf{w}} \cdot \nabla T+P=0
$$

and after modifications

$$
\frac{\partial}{\partial x}\left(\lambda_{R} \frac{\partial T}{\partial x}\right)+\frac{\partial}{\partial y}\left(\lambda_{T} \frac{\partial T}{\partial y}\right)+\frac{\partial}{\partial z}\left(\lambda_{L} \frac{\partial T}{\partial z}\right)+c_{w} Q_{w} \frac{\partial T}{\partial z}+P=0,
$$

where $\lambda_{T}, \lambda_{R}$ and $\lambda_{L}$ are thermal conductivities in the tangential, radial and longitudinal anatomical directions of wood. 


\section{Two-needle measuring system}

The analyzed measuring system is partially similar to Leyton and partially to HFD ones. It consisted of the two needle heaters (a resistance wire inserted in the stainless hypodermic needle $1.5 \mathrm{~mm}$ in outer diameter and inner $1.0 \mathrm{~mm}$ ) situated in the sapwood below cambium (bark surface) and several thermocouples copper-constantan, with measuring points at different arrangements and distances from the heaters (the distance step is $5 \mathrm{~mm}$ - see Figure 1). Total resistance of the heater wire is $60.5 \Omega\left(204.8 \Omega \mathrm{m}^{-1}\right)$ and applied direct current voltage is 4.24 (low heating) or 5.83 (high heating). This gives the power $\left(\mathrm{U}^{2} / \mathrm{R}\right)=0.297$ or $0.652 \mathrm{~W}$ per the entire needle, respectively. It means approximately a power of $6-10 \mathrm{~W} / \mathrm{m}$ (Watt per meter needle length) according to operating length of the heating wire. The value of $8 \mathrm{~W} / \mathrm{m}$ was used for numerical simulation in this work. We tested different combinations of temperature differences and the best relations with sap flow was found for the following three combinations (A, B, C-Figure 1).

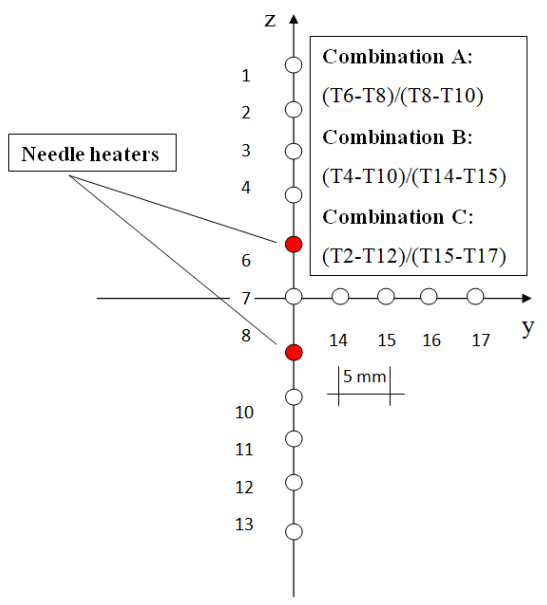

Figure 1: Scheme of sensor situated in the middle of the sapwood.

\section{Results and discussion}

In Figure 2 you can see the temperature field as the result of three-dimensional finite element model for heat conductivity $\lambda_{T}=0.3 \mathrm{~W} \mathrm{~m}^{-1} \mathrm{~K}^{-1}$ and sap flow density $Q_{w}=0.03 \mathrm{~kg} \mathrm{~m}^{-2} \mathrm{~s}^{-1}$.

We performed a numerical solution of the partial differential equation for different sap flow values and also for three different heat conductivities. We were observing temperature differences between heated and non-heated state in several points around the heated area and then observing the dependence of these temperature differences and their combinations on sap flow for three different values of heat conductivities. 


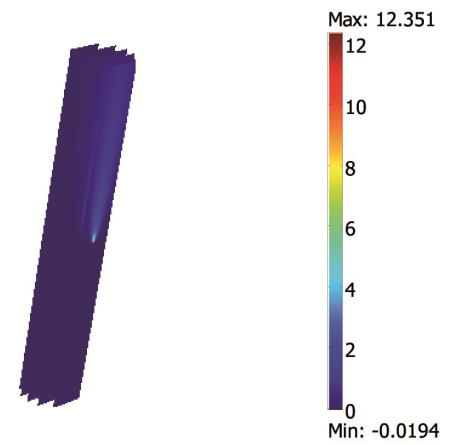

Figure 2: Three-dimensional illustration of temperature field for heat conductivity $\lambda_{T}=0.3 \mathrm{~W} \mathrm{~m}^{-1} \mathrm{~K}^{-1}$ and sap flow density $Q_{w}=0.03 \mathrm{~kg}$ $\mathrm{m}^{-2} \mathrm{~s}^{-1}$.

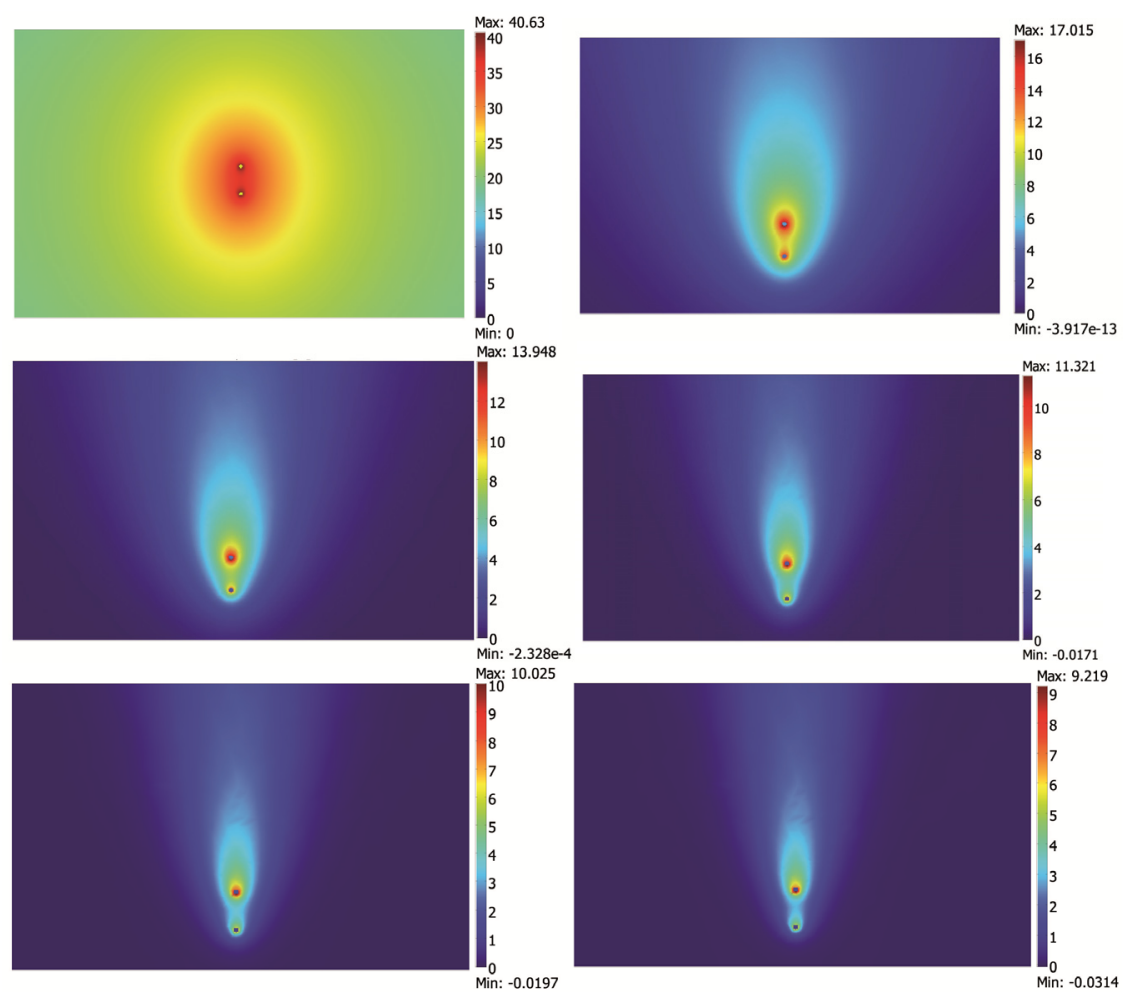

Figure 3: Numerical simulations of temperature field for heat conductivity $\lambda_{T}=0.3 \mathrm{~W} \mathrm{~m}^{-1} \mathrm{~K}^{-1}$ and for different values of sap flow $Q_{w}(0$, $0.01,0.02,0.04,0.06,0.08$ ) in plane of sensor (in the middle of the sapwood). Note: read from the left to the right and from the top to the bottom for individual Qw. 
We compared dependences of several combinations of temperature differences on sap flow and we are presenting the results of the best three combinations (A, B, C - see Figure 1).

In combination $\mathrm{A}$, the result was the best one of the three good chosen combinations and thus we tried to find out the formula that could describe the relation between temperature differences, heat conductivities and sap flow.

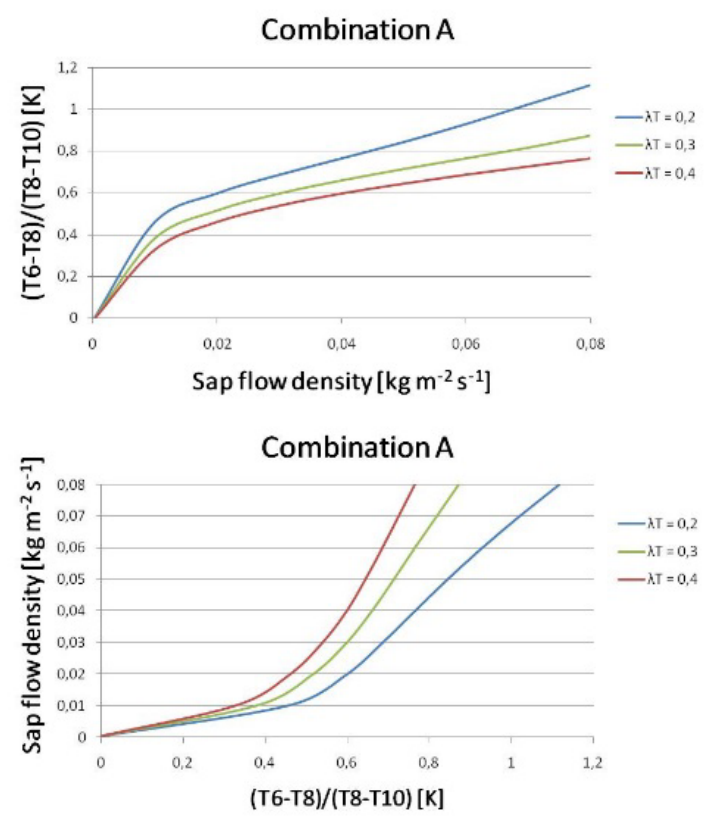

Figure 4: Dependence of combination of temperature differences (A) on sap flow density (left panel) and dependence of sap flow density on the combination of temperature differences (A) (right panel).

We recommend the following formula for sap flow calculation:

$$
Q_{w}=a\left(\lambda_{T}\right) e^{\left(b\left(\lambda_{T}\right) \frac{T 6-T 8}{T 8-T 10}\right)}+c\left(\lambda_{T}\right),
$$

where

$$
a\left(\lambda_{T}\right)=0.026-0.058 \lambda_{T}, b\left(\lambda_{T}\right)=-0.511+11.33 \lambda_{T}, c\left(\lambda_{T}\right)=0.031-0.07 \lambda_{T} .
$$

The derived formula (5) was verified by the simulations. The result of this step is presented at the graph (Figure 5). The graph shows that the results from the formula are consistent across whole testing range of sap flux densities for all chosen values of heat conductivity. 


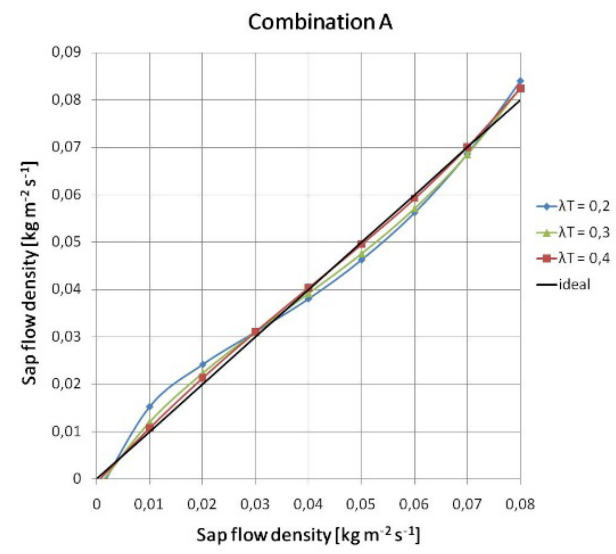

Figure 5: Relation between input and output (from formula (5)) sap flow density for three different heat conductivities of wood.

No formula was searched for in the remaining two combinations and "only" graphs were created (Figure 6). The graphs show the dependence between temperature differences and the transpiration flow for three different wood heat conductivities.
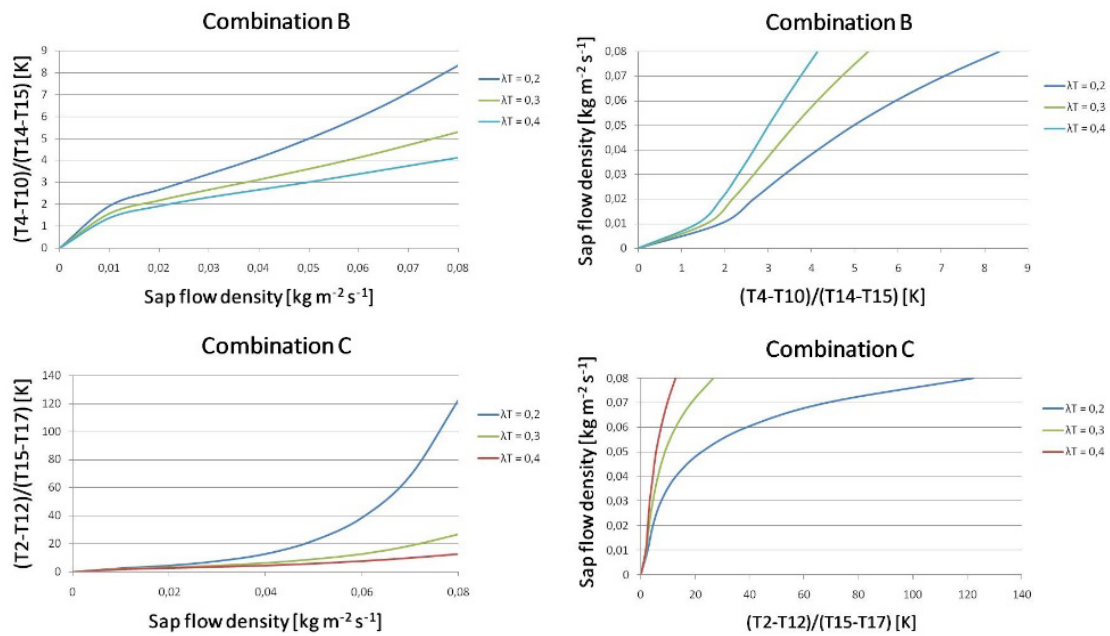

Figure 6: Dependence of combination of temperature differences (B) on sap flow density (upper, left panel) and dependence of sap flow density on the combination of temperature differences (B) (upper, right panel). Dependence of combination of temperature differences (C) on sap flow density (lower, left panel) and dependence of sap flow density on the combination of temperature differences (C) (lower, right panel). 


\section{Conclusion}

This paper deals with the mathematical modelling and the numerical simulation of the temperature field around two heated needles inserted into sapwood of a tree stem. The resulting temperature field is dependent on conduction and convection of heat. Heat convection is caused by sap flow that cools and also deforms the resulting temperature field.

The aims of this paper are to show the dependence of the measurable temperature differences by thermocouples on different values of sap flow during two-needle heating and to discuss the usage of this system for sap flow measurement at trees.

\section{Acknowledgements}

The work was supported by OP Education for Competitiveness (European Social Fund and the state budget of the Czech Republic) CZ.1.07/2.3.00/30.0017 Postdocs in Biological Sciences at MENDELU.

\section{References}

[1] Baker, J.M. \& Van Bavel, C.H.M., Measurement of mass flow of water in stems of herbaceous plants. Plant Cell Environ, 10, pp. 777-782, 1987.

[2] Caspari, H.W., Green, S.R. \& Edwards, W.R.N., Transpiration of well watered and water-stressed Asian pear trees as determined by lysimetry, heat-pulse and estimated by a Penman Monteith model. Agric For Meteorol, 67, pp. 13-27, 1993.

[3] Čermák, J., Deml, M. \& Penka, M., A new method of sap flow rate determination in trees. Biol. Plant. Praha, 15(3), pp. 171-178, 1973.

[4] Čermák, J. \& Deml, M., Method of water transport measurements in woody species, especially in adult trees (in Czech). Patent (Certification of authorship) CSFR, No. 155622 (P.V.5997-1972), 1974.

[5] Cohen, Y., Fuchs, M. \& Green, G.C., Improvement of the heat pulse method for determining sap flow in trees. Plant Cell Environ, 4, pp. 391397, 1981.

[6] Cohen, Y., Thermoelectric methods for measurement of sap flow in plants. In: Standhill G (ed) Advances in bioclimatology. Springer, Berlin Heidelberg New York, pp. 63-89. 1993.

[7] Granier, A., Une nouvelle methode pour la mesure dy flux de seve brute dans le trons des arbres. Ann Sci For, 22, pp. 193-200, 1985.

[8] Green, S., Clothier, B., Jardine, B., Greven, M., Neal, S., Caspari, H. \& Dichi, B., Measurements of sap flow in grape wines. In: Tognetti R, Raschi A (eds) Proceedings of 5th International Workshop "Plant Water Relations and Sap Flux Measurements”, Firenze, Italy, Nov 9-10, 2000, pp. 123-153, 2003.

[9] Green, S.R. \& Clothier, B.E., Water use of kiwifruit vines and apple trees by the heat-pulse technique. J Exp Bot, 39, pp. 115-123. 1998. 
[10] Huber, B., \& Schmid,t E., Weitere thermoelektrische Untersuchungen uber den Transpirationsstrom der Baume. Tharandt Forstl Jahrb, 87, pp. 369-412, 1936.

[11] Huber, B., Beobachtung und Messung pflanzlicher Saftstrome. Ber Dtsch Bot Ges, 50, pp. 89-109, 1932.

[12] Leyton, L., Continuous recording of sap flow rates in tree stems. IUFRO Meetings, 240-249, 1967.

[13] Leyton, L., Remove from marked records problems and techniques in measuring transpiration from trees. Physiology of tree crops, 101-111, 1970.

[14] Marshall, D.C., Measurements of sap flow in conifers by heat transport. Plant Physiol, 33, pp. 385-396, 1958.

[15] Morikawa, Y., The heat pulse method and apparatus for measuring sap flow in woody plants. Jpn For Soc, 54, pp. 166-171, 1972.

[16] Nadezhdina, N., Čermák, J. \& Nadezhdin V., Heat field deformation method for sap flow measurements. Proc. 4th. International Workshop on Measuring Sap Flow in Intact Plants. Židlochovice, Czech Republic, Oct. 3-5, 1998. 72-92. IUFRO Publications. Publishing house of Mendel Univ.Brno. 1998.

[17] Nadezhdina, N. \& Čermá, J., "The technique and instrumentation for estimation the sap flow rate in plants". Patent No. 286438 (PV-1587-98). 1998.

[18] Nadezhdina, N., Vandegehuchte, M.W. \& Steppe, K., Sap flux density measurements based on the heat field deformation method. Trees, 26 (5), pp. 1439-1448, 2012.

[19] Sakuratani, T., A heat balance method for measuring water flux in the stem of intact plants. J Agric Meteorol (Jpn), 37, pp. 9-17, 1981.

[20] Sakuratani, T., Improvement of the probe for measuring water flow rate in intact plants with the stem heat balance method. J Agric Meteorol (Jpn), 40, pp. 273-277, 1984.

[21] Swanson, R.H., Sampling for direct transpiration estimates. J Hydrol (Dunedin), 9, pp. 72-77, 1970.

[22] Tatarinov, F.A., Kučera, J. \& Cienciala, E., The analysis of physical background of tree sap flow measurements based on thermal methods. Measurements Science and Technology, 16, pp. 1157-1169, 2005.

[23] Trcala, M. \& Čermák, J., Improvement of the trunk heat balance method including measurements of zero and reverse sap flows. Agricultural and Forest Meteorology, 166-167, pp. 120-126, 2012.

[24] Trcala M., Čermák J. 2014 Nonlinear finite element analysis of thermal inertia in heat-balance sap flow measurement. International Journal of Thermal Sciences, 76, pp. 200-207, 2014.

[25] Vandegehuchte, M.W. \& Steppe, K., Sap flux density measurement methods: working principles and applicability. Functional Plant Biology, 40(3), pp. 213-223, 2012. 